\title{
Mercado de trabalho nos meios de hospedagem: oferta e demanda de vagas
}

Creici Lamonato. Mestre em Psicologia. Faculdade de Tecnologia Senac Chapecó - Brasil. creici-lamonato@hotmail.com

Kellen Lazzarotti. Mestre em Administração. Faculdade de Tecnologia Senac Chapecó - Brasil. kellen.lazzaretti@sc.senac.br

\section{RESUMO}

O mercado de trabalho nas organizações está relacionado com a oferta e demanda de vagas de emprego e tende a ser um fenômeno que envolve uma variedade de fatores internos e externos à organização. Diante disso, envolve processos organizacionais, como por exemplo, atração e seleção de pessoas, que necessitam de constante aperfeiçoamento e evolução para garantir eficiência e eficácia organizacional. O objetivo geral da pesquisa foi examinar a correspondência entre oferta e demanda das vagas de trabalho na esfera de atuação dos meios de hospedagem. Para atender o objetivo proposto investigou-se 16 organizações do segmento de Turismo do estado de Santa Catarina. A pesquisa foi caracterizada como quantitativa e qualitativa, de caráter exploratório. A coleta de dados foi efetuada por meio de um questionário com perguntas de múltipla escolha enviado on-line. A oferta e demanda de vagas nos meios de hospedagem exige dos processos de gestão de pessoas constante renovação, uma vez que se identificou a necessidade de aperfeiçoamento dos processos de atração e seleção de pessoas e de planejamento de pessoal. Além disso, o segmento de Turismo carece de pessoal com as qualificações necessárias para as demandas do mercado de trabalho.

Palavras-chave: Mercado de trabalho. Meios de hospedagem. Vagas de trabalho. Seleção de pessoas.

\section{Labour market in the hospitality area: supply and demand of vacancies}

\begin{abstract}
The labor market in organizations is related to the supply and demand of job vacancies and tends to be a phenomenon involving a variety of internal and external factors in the organization. This involves organizational processes, such as attraction and selection of people who require constant training and development to ensure organizational efficiency and effectiveness. The objective of this research was to analyze the correlation between supply and demand of job vacancies in the sphere of action of accommodation facilities. To achieve the proposed objective, 16 organizations of the segment of Tourism in Santa Catarina State were studied. The research was characterized as quantitative, qualitative and exploratory. Data collection was conducted through a questionnaire with multiple choice questions submitted online. The supply and demand of jobs in the accommodation environment requires constant renewal in the processes of personnel management, since it identified the need for improvement in what concerns the attraction and selection processes of people and personnel planning. In addition, the Tourism segment lacks people with the conditions and qualifications needed for efficient operations and satisfactory level of quality.
\end{abstract}

Keywords: Labor market. Means of accommodation. Job vacancies. Attracting people. Selection of people. 


\section{INTRODUÇÃO}

O turismo tem se destacado no cenário brasileiro por apresentar índices de crescimento tanto nacional como internacional. Diante disso, é notável o significativo desenvolvimento social, como por exemplo a oferta e demanda de vagas de trabalho. O mercado de trabalho é composto pelas oportunidades de trabalho oferecidas pelas empresas, tendo um caráter dinâmico e condicionado a inúmeros fatores, dentre eles: a situação econômica da região, a natureza e a qualidade dos postos de trabalho, a produtividade e a inserção no mercado internacional.

Ao longo da revolução industrial, o mercado de trabalho substituiu as fazendas pelas fábricas e a composição do emprego que era estável e permanente, passou a ser caracterizada - na era da informação - com mobilidade de empregados. Houve migração do emprego da indústria para o setor de serviços, do assalariado formal para o informal, além do aumento do trabalho autônomo. Tem-se desse modo, na era da revolução da informação, que o mercado de trabalho se deslocou rapidamente do setor industrial para a economia de serviços, sendo este setor responsável pelo aumento da oferta de empregos. (CHIAVENATO, 2004). Um dos ramos do setor de serviços que tem contribuído significativamente para este aumento é o de turismo.

Dados do World Travel \& Tourism Council (WTTC) coletados em 25 países, dentre eles o Brasil, revelam que o setor de Viagens e Turismo, em 2013, contribuiu mais para o PIB do que a indústria de automóveis em qualquer região do mundo, sendo que nas Américas, especificamente, três vezes mais (WTTC, 2013). A chegada de turistas internacionais de todos os países do mundo cresceu $4,7 \%$ de janeiro a dezembro de 2014. Este crescimento foi identificado em todas as regiões do mundo, em que as Américas lideram o ranking, com um crescimento de 7,4\% no ano (WTTC, 2013). O Relatório de estatísticas básicas de turismo, publicado pelo Ministério do Trabalho e Emprego em 2013 aponta que o número de turistas internacionais na América do Sul foi de 27,4 milhões, $0,74 \%$ a mais do que 2012. Enquanto no Brasil o número foi de 5,8 milhões, 1,99\% a mais do que 2012, localizando o país em 45a colocação em nível mundial, que tem a França como principal receptor, seguido dos Estados Unidos. A maioria desses turistas (2,9 milhões) que vem ao Brasil é oriunda de outros países da América do Sul, principalmente da Argentina (BRASIL, 2013).

Com o aumento da entrada de turistas no Brasil, aumentou também a oferta hoteleira. Dados de 2013 revelam que o número de meios de hospedagem aumentou 17,5\% de 2012 para 2013, as unidades habitacionais aumentaram $18,1 \%$ e os leitos $17,9 \%$, no mesmo período (BRASIL, 2013).

Com índices econômicos tão positivos, o setor de turismo e viagens gerou um impacto total de $8,8 \%$ no emprego mundial. Este setor é um dos principais criadores de emprego em todo o mundo. Sustentou 266 milhões de empregos em 2013, excedendo o número gerado pelo setor de produtos químicos, bancários, mineração, manufatura automotiva, e ensino superior. Nas Américas, em 2013, o setor empregou 30 milhões de pessoas, sustentando diretamente mais empregos do que os setores de mineração, comunicação, educação, educação superior, serviços financeiros e bancários (WTTC, 2013). Como se observa, o crescimento do setor aumenta também a demanda por mão de obra. A área do turismo é uma importante fonte geradora de emprego também no Brasil.

A Organização Mundial do Turismo revela que no Brasil um em cada 11 empregos gerados em 2014 foram na área de Turismo (IPEA, 2015). Mas não foi somente em 2014 que este setor do mercado de trabalho cresceu. Ele vem nessa constante há alguns anos. Entre 2006 e 2013, o índice de evolução da ocupação nas Atividades Características do Turismo (ACTs) teve um acréscimo de 203 mil. No Brasil, em dezembro de 2013, as ACTs empregavam 1,939 milhão de pessoas, sendo que destas $51 \%$ eram empregos formais e $49 \%$ informais. As regiões do país que tiveram maior 
participação nesse crescimento foram a Sudeste, que em 2013 respondia por 51\% das ocupações no setor de turismo, seguida pela região Nordeste, com $23 \%$. O Sul do Brasil ficou em $3^{\circ} \mathrm{com} 13 \%$. Se fragmentadas as ACTs, têm-se que as atividades de Alimentação (52,1\%), Transporte Terrestre $(19,4 \%)$ e Alojamento $(16,4 \%)$ foram as mais significativas na composição da ocupação no turismo (IPEA, 2015).

Os dados apresentados até o momento, demonstram que há um crescimento do número de ocupações na área de turismo no Brasil e uma tendência em sua continuidade. Se considerados os eventos previstos, como as Olimpíadas em 2016, pode-se prever um aumento na demanda de profissionais nesta área. Observa-se também, que uma das atividades que tem contribuído significativamente para este crescimento é a de alojamento. Isso significa que os meios de hospedagem, que operacionalizam a atividade de alojamento, têm contribuído para a manutenção desses dados crescentes.

Considerando esse contexto, a pesquisa tem como objetivo geral examinar a correspondência entre oferta e demanda das vagas de trabalho na esfera de atuação dos meios de hospedagem. Seus objetivos específicos são: 1) investigar os recursos de atração e seleção de profissionais mais adotados nos meios de hospedagem, 2) identificar as vagas ofertadas e demandadas para atuação nos meios de hospedagem, 3) identificar a disponibilidade de profissionais para contratação nas vagas ofertadas e demandadas.

\section{MERCADO DE TRABALHO NO MEIOS DE HOSPEDAGEM}

As pessoas constituem um dos principais recursos das organizações, uma vez que se considera que é o ativo humano que movimenta os demais recursos organizacionais. No setor de meios de hospedagem, o ativo humano ainda se constitui no bem mais importante em virtude das características do negócio e sua relação com às necessidades do cliente, seja em momentos de lazer, divertimento ou negócios. Nesse sentido, conhecer os cargos com maior disponibilidade nos meios de hospedagem de vagas e algumas dificuldades relacionadas à atração e seleção de pessoas possibilita o desenvolvimento de estratégias que favorecem a manutenção desse negócio.

Compreender a dinâmica do mercado de trabalho é fundamental para decisões relativas aos subsistemas de gestão de pessoas. Segundo Dutra (2002, p. 70), o mercado de trabalho pode ser definido "como o conjunto de oportunidades de trabalho oferecido pelas organizações e como o conjunto das pessoas dispostas a oferecer sua força". No entanto, o autor ressalta que esse é um conceito simplista, podendo gerar equívocos. Dutra (2002) sugere que o mercado de trabalho possa ser considerado como um espaço de negociação e de troca suprindo necessidades do indivíduo e de uma organização. Além disso, o mercado de trabalho pode ser constituído "pelos espaços criados pelas próprias pessoas e pela dinâmica do mercado" (DUTRA, 2002, p. 70). Diante disso é possível verificar que a dinâmica do mercado de trabalho vai muito além da disponibilidade de vagas versus disponibilidade de pessoas ou candidatos. É um processo que envolve necessidades sociais, físicas e psicológicas do indivíduo, bem como necessidades organizacionais. A satisfação das necessidades das duas partes e o contexto é o que gera a dinâmica cíclica dessa relação.

Segundo Albuquerque e Leite (2009) o mercado de trabalho pode ser considerado uma relação de troca onde o indivíduo oferta a força de trabalho e as organizações que demandam as vagas de trabalho. A oferta da força de trabalho está relacionada a um conjunto de competências individuais, além da disponibilidade do indivíduo para o trabalho. Já a demanda de vagas de trabalho está relacionada a capacidade do empregador em relação à remuneração, benefícios e 
status. Diante disso, verifica-se que a relação de troca entre empregado e empregador é quem determina o funcionamento do mercado de trabalho, sendo influenciado por determinantes tecnológicos, culturais, demográficos, sociais, políticos e legais.

Um dos instrumentos reguladores da relação entre empregado e empregador é o contrato de trabalho. De acordo com Albuquerque e Leite $(2009$, p. 56$)$ é por meio do contrato que "as partes estabelecem as condições de compra e venda da mercadoria força de trabalho. Ao comprador compete o pagamento de um valor estabelecido ao vendedor, durante a vigência do contrato". Dessa maneira está caracterizado o mercado de trabalho formal, onde a relação é estabelecida e definida anteriormente. Mas como se comporta essa relação de contrato nos meios de Hospedagem? De acordo com a pesquisa de Índice de Competitividade do Turismo Nacional realizada pela FGV/Mtur e Sebrae (2004) a mão de obra informal é característica desse setor. Verifica-se, segundo o organizador do estudo Luiz Gustavo Medeiro Barbosa, que na área de Turismo as relações de trabalho ainda atuam na informalidade; ou seja, sem contrato entre as partes. Isso corrobora com um dos marcos conjunturais relacionados ao mundo trabalho citado por Zanelli, Borges-Andrade e Bastos (2004, p. 55) que é o "surgimento do desemprego estrutural e dissociação entre crescimento econômico e crescimento da oferta de emprego". Segundo dados coletados em 2011 e apresentados pelo IPEA (2014) sobre o perfil da mão de obra no turismo 47\% das vagas são formais e $53 \%$ das vagas no turismo são informais.

Albuquerque e Leite (2009) analisaram um modelo estrutural de mercado de trabalho proposto por Offe e Hinrich (1984) que está subdivido em quatro grupos. O primeiro grupo é constituído pelas partes "inativas" da população, ou seja, aquele grupo de pessoas que não possuem condições de trabalhar, como crianças, doentes etc. O segundo grupo é caracterizado pelas pessoas que não mantêm uma relação de trabalho formal (com contrato de trabalho) e são denominados de "desempregados". As pessoas que possuem uma relação formal de trabalho (com contrato de trabalho) fazem parte do terceiro grupo chamado de "empregados". O quarto grupo é identificado pelas pessoas ativas, os "autônomos", tais como profissionais liberais, consultores, artistas etc. Essa divisão demonstra a complexidade e a dinâmica do mercado de trabalho.

As relações de trabalho modificam-se de acordo com o cenário econômico, geográfico, social e seu contexto. Em alguns momentos o mercado de trabalho apresenta uma oferta de vagas de trabalho mais elevada e em outros momentos menos elevada, cujo efeito resulta em abundância ou escassez de pessoas disponíveis no mercado. Nos meios de hospedagem isso é bastante acentuado conforme mudam as estações do ano. Dutra (2002) chama atenção quando uma organização observa o mercado somente quando necessita de recursos ou quando estão escassos. Isso resulta na falta de percepção total do mercado e não permite visualizar oportunidade e ameaças do negócio gerando perda de eficiência organizacional. Diante disso, parece ser fundamental que a área de meios de hospedagem busque estar atenta a dinâmica do mercado em relação às pessoas.

Em relação à evolução do emprego no turismo no Brasil entre 2006 e 2011 segundo IPEA (2014, p. 20) houve "um aumento de $21 \%$ no emprego de homens no turismo e, contra $55 \%$ no de mulheres" evidenciando um avanço relevante da participação feminina no mercado de trabalho do turismo no Brasil. Os dados revelam uma modificação nas características relacionadas a empregabilidade no turismo, tendo como destaque a inserção de pessoas do sexo feminino com maior efetividade. Albuquerque e Leite (2009) sinalizam que a gestão estratégica de pessoas necessita estar atenta para as diversas forças reguladoras do mercado de trabalho (econômicas, culturais, demonográficas, tecnológica etc.), mas também precisa estar atenta às características específicas da força de trabalho, tais como gênero, idade, aspectos comportamentais e culturais, entre outros. 
De acordo com o IPEA (2014, p. 42) "uma das carências relacionadas ao mercado de trabalho do turismo está vinculada à qualificação profissional [...]. Para superá-la, é necessário conhecer a dimensão, o perfil e onde está alocada espacialmente esta mão de obra". Isso evidencia uma possível implicação nas áreas relacionadas a gestão de pessoas.

\subsection{Implicações do mercado de trabalho na gestão de pessoas}

As oscilações do mercado de trabalho podem influenciar diretamente as práticas de gestão de pessoas. Quando o mercado de trabalho possui abundância de oportunidade de emprego pode gerar uma escassez na força de trabalho disponível. A escassez de mão de obra gera dificuldades diretas nos processos de atração e seleção de pessoas, pois a disputa pelos empregados aumenta e diminui a quantidade de força de trabalho disponível. Além disso, pode ocasionar falta de pessoas para ocupar as vagas nas organizações, comprometendo assim a competitividade de seus produtos e serviços. Diante disso, cabe ao profissional de recursos humanos dos meios de hospedagem identificar as principais dificuldades na contratação de pessoal e criar estratégias de atração e seleção, nas circunstâncias parecidas.

Uma das estratégias está relacionada às fontes de atração de pessoas que podem ser diferenciadas entre atração externa ou atração interna. Segundo Banov (2004) no processo de atração externo ocorre a busca de pessoas no mercado de trabalho, sendo que na atração interna são aproveitadas pessoas que já fazem parte da organização por meio de promoções e transferências. As duas estratégias podem gerar resultados positivos se conduzidos de maneira adequada e com os cuidados necessários como por exemplo, escolher os locais de divulgação da vaga acessíveis ao público que se deseja atingir.

Existe uma variedade de fontes de atração que podem ser utilizadas para atrair candidatos as vagas que necessitam ser preenchidas. Dentre elas destacam-se: sites corporativos ou de empregos; anúncios em jornais, revistas especializadas, rádio, televisão; anúncios em locais visíveis e de grande circulação, utilização de agências de emprego ou headhunting (profissional que capta talentos no mercado de trabalho para as organizações), entidade de classe (sindicatos, associações e conselho de classes); escolas, faculdades e universidades; fusões de incorporações (união de duas ou mais empresas que se extinguem formando uma nova e única grande empresa), bancos de talentos, redes sócias e internet e cadastro de ex-empregados, dentre outras.

Outra estratégia utilizada na contratação de pessoas está relacionada ao processo de seleção. De acordo com Banov (2004) é por meio da seleção que é possível escolher e ter uma previsão do desempenho dos candidatos de acordo com as necessidades do cargo. Há uma variedade de estratégias para a avaliação dos candidatos, no entanto as mais utilizadas são: testes psicológicos, testes de conhecimentos, entrevistas e técnicas de simulação (dinâmicas de grupo, jogos, debates, estudos de caso e role playing). As estratégias de seleção podem ser combinadas entre si, garantindo uma maior confiabilidade na avaliação dos candidatos.

Preencher uma vaga de trabalho em uma organização nem sempre é uma tarefa simples. Segundo Banov (2004) envolve a definição do perfil do cargo, o processo de recrutamento, seleção de pessoal e treinamento. Essas atividades possuem características distintas que necessitam ser dominadas pelos profissionais da área de gestão de pessoas. Diante disso, o principal desafio do recrutamento e seleção no mercado de hoje é a capacidade de atrair e reter talentos. Mais do que nunca, é preciso apropriar-se das novas técnicas e tecnologias além de ampliar e mudar o foco da área de gestão de pessoas de questões burocráticas para uma concepção mais estratégica.

De acordo com Albuquerque e Leite (2009, p. 70) "a capacidade da área de gestão de pessoas para atrair e reter os colaboradores [...] está diretamente associada ao grau de 
conhecimento que detém sobre os mercados de trabalho com os quais interage". Nesse sentido verifica-se a necessidade de a área de gestão de pessoas estar acompanhando constantemente as mudanças do mercado de trabalho. Para Vieira, Pereira e Lima $(2007$, p. 79) um dos maiores desafios da área de recursos humanos no setor turístico está na "implantação de estratégias, planos e programas para atrair, motivar, desenvolver, remunerar e reter as melhores pessoas para cumprir metas organizacionais e objetivos operacionais".

Mas como atrair e reter profissionais não é uma pergunta fácil de ser respondida, pois exige a análise de uma variedade de aspectos relacionados ao empregado e ao empregador. Um desses aspectos é conseguir candidatos para as vagas disponíveis. De acordo com Spector (2004) as organizações deveriam empregar esforços consideráveis para atrair pessoas, pois quando há poucos candidatos o processo de escolha fica deficiente. Nesse sentido, o processo de atração de pessoas requer atenção pois segundo Gil (2010) é por meio desse processo que é possível atrair candidatos potencialmente qualificados. Diante disso, parece ser fundamental que as organizações criem estratégias para que os candidatos se disponibilizem para as vagas de emprego.

Outro aspecto relacionado ao processo de atração e retenção de pessoas é o funcionamento dos procedimentos de recrutamento e seleção. Existem várias etapas para que o processo ocorra de maneira adequada. Dentre elas destacam-se: planejamento de necessidade de pessoal, definição de perfil (competências), definição de estratégias de atração, definição de fonte de atração, triagem dos currículos dos candidatos, definição de estratégias de avaliação (seleção), avaliação dos candidatos, escolha do candidato e retorno da avaliação aos candidatos. Quando essas etapas não são realizadas efetivamente podem interferir na retenção de pessoas nas organizações, pois não haverá uma uniformidade, padronização e, consequentemente, qualidade nos procedimentos.

De acordo com Mello et al (2011) em estudo realizado no setor capixaba os processos de recrutamento e seleção têm características semelhantes entre os hotéis, que se caracterizam por recebimento de currículo via site ou na recepção do hotel, triagem de currículos, entrevistas, testes (práticos e psicológicos) e dinâmicas de grupo. Os dados corroboram com as etapas descritas por Gil (2010) relativas à divulgação da vaga internamente ou externamente, análise de currículo, aplicação de testes, realização de entrevista, dinâmicas de grupo, avaliação do candidato e tomada de decisão.

Para França (2010) o processo de recrutamento e seleção possui um papel fundamental na renovação ou confirmação das estratégias adotadas pela organização, pois quando há falta de pessoal compromete diretamente a eficiência organizacional, além da qualidade dos serviços. Diante disso, parece ser fundamental que o processo de atração e seleção possua um status de melhoria contínua, ou seja, com possibilidades de inovação e de diferenciação, possibilitando assim a manutenção dos indivíduos para a organização.

\section{PROCEDIMENTO METODOLÓGICO}

Esta pesquisa é exploratória, pois tem o objetivo de examinar a correspondência entre oferta e demanda das vagas de trabalho na esfera de atuação dos meios de hospedagem. De acordo com Gil (2002), estas pesquisas têm como objetivo proporcionar maior familiaridade com o problema, tornando mais explícito ou construindo hipóteses, além de aprimorar ideias ou a descoberta de intuições.

O estudo caracterizou-se como qualitativo e quantitativo, pois buscou verificar a opinião e comportamentos dos meios de hospedagens do estado de Santa Catarina. Segundo Silva e 
Menezes (2001) a pesquisa quantitativa pode traduzir em números opiniões e informações para classificá-las e analisá-las, e requer o uso de recursos e de técnicas estatísticas (percentagem, média, moda, mediana etc.). Já a pesquisa qualitativa é descritiva e os principais focos de sua abordagem são o seu processo e significado.

Segundo Lakatos e Marconi (2001) amostra é uma porção ou parcela do universo que foi selecionada. A fim de responder os objetivos da pesquisa participaram da coleta de dados 16 organizações do segmento de Turismo do estado de Santa Catarina, sendo que todos estavam cadastrados no Cadastur (Ministério do Turismo). Os questionários foram enviados por e-mail (correio eletrônico) para todas as organizações cadastradas no Cadastur. Ao final do período (90 dias) houve a aderência de 16 organizações.

O instrumento de coleta de dados utilizado foi um questionário composto de 12 (doze) perguntas de múltipla escolha que buscaram investigar aspectos relacionados a oferta e demanda de vagas de emprego. Por exemplo foi perguntado quais as vagas de trabalho com maior dificuldade de contratação e quais as vagas de trabalho com maior facilidade de contratação nos meios de hospedagem.

A coleta dos dados ocorreu no período de 23/09/2015 a 18/11/2015. As informações foram sistematizadas e tabuladas para melhor interpretação e entendimento dos resultados. Para Lakatos e Lakatos (2001) a tabulação consiste em dispor os dados em tabelas para facilitar a verificação das inter-relações entre eles, permite sintetizar os dados de observação e representá-los graficamente, de forma a serem mais bem compreendidos e interpretados mais rapidamente. Após os dados foram analisados e interpretados de acordo os objetivos propostos.

\section{ANÁLISE DE RESULTADOS}

A coleta de dados sobre oferta e demanda de vagas de trabalho nos meios de hospedagem foi realizada com base nos dados de 16 questionários respondidos por profissionais de organizações do segmento de Turismo. Destas organizações, 50\% foram classificados segundo o Cadastur como hotel, $19 \%$ como pousada, $12,5 \%$ como albergue, $12,5 \%$ como hotel fazenda e $6 \%$ como hotel com restaurante.

Os questionários foram respondidos considerando: $31 \%$ Gestores de Recursos Humanos, $31 \%$ por Gerentes de Meio de Hospedagens, 19\% por Auxiliares de Recursos Humanos, 13\% por Gestores da Área Administrativa e $6 \%$ por proprietários. Verifica-se que 50\% dos questionários foram respondidos por profissionais específicos da área de Gestão de Pessoas e 50\% por profissionais de outras áreas.

Em relação a categoria "vagas de trabalho com maior dificuldade de contratação" identificou-se uma variedade de cargos que apresentam dificuldades como pode ser visualizado na tabela 1. Os dados demonstram que existe uma carência de pessoas em várias especialidades dos meios de hospedagem, não se restringindo a cargos específicos.

Tabela 1 - Vagas de trabalho com maior dificuldade de contratação.

\begin{tabular}{lcc}
\hline Vaga & Quantidade & Porcentagem \\
\hline Arrumadeira & 5 & $9,4 \%$ \\
Cozinheiro & 4 & $7,5 \%$ \\
Gerente Geral & 4 & $7,5 \%$ \\
Agente de Hotel & 3 & $5,7 \%$ \\
Ajudante de Arrumadeira & 3 & $5,7 \%$ \\
Ajudante de Rouparia & 3 & $5,7 \%$
\end{tabular}




\begin{tabular}{lll} 
Atendente de Hotel & 3 & $5,7 \%$ \\
Garçom & 3 & $5,7 \%$ \\
Assistente de Governança & 2 & $3,8 \%$ \\
Capitão Porteiro & 2 & $3,8 \%$ \\
Executivo de Contas de Hotel & 2 & $3,8 \%$ \\
Faxineiro & 2 & $3,8 \%$ \\
Governanta & 2 & $3,8 \%$ \\
Recepcionista de Hotel & 2 & $3,8 \%$ \\
Auxiliar de Cozinha & 2 & $3,8 \%$ \\
Encarregado de Turno & 1 & $1,9 \%$ \\
Lavador de Roupas & 1 & $1,9 \%$ \\
Supervisor de Recepção & 1 & $1,9 \%$ \\
Caixa & 1 & $1,9 \%$ \\
Líder de Recepção & 1 & $1,9 \%$ \\
Assistente de Reservas & 1 & $1,9 \%$ \\
Caseiros & 1 & $1,9 \%$ \\
Coordenador de A\&B & 1 & $1,9 \%$ \\
Auxiliar de Lavanderia & 1 & $1,9 \%$ \\
Mensageiro & 1 & $1,9 \%$ \\
Manutenção Predial & 1 & $1,9 \%$ \\
\hline
\end{tabular}

Fonte: Elaborado pelos autores (2016)

Na categoria "vagas de trabalho com maior facilidade de contratação" verificou-se também uma variedade de cargos citados, sendo que os cargos com maior destaque: arrumadeira, caixahotelaria, recepcionista de hotel e assistente de reserva conforme apresenta a tabela 2.

Tabela 2 - Vagas de trabalho com maior facilidade de contratação.

\begin{tabular}{lcc}
\hline Vaga & Quantidade & Porcentagem \\
\hline Arrumadeira & 5 & $10 \%$ \\
Caixa - Hotelaria & 4 & $8 \%$ \\
Recepcionista de Hotel & 4 & $8 \%$ \\
Assistente de Reservas & 4 & $8 \%$ \\
Faxineiro & 3 & $6 \%$ \\
Auxiliar de Cozinha & 3 & $6 \%$ \\
Ajudante de Arrumadeira & 3 & $6 \%$ \\
Garçom & 3 & $6 \%$ \\
Manobrista & 3 & $6 \%$ \\
Auxiliar de Lavanderia & 2 & $4 \%$ \\
Segurança & 2 & $4 \%$ \\
Agente de Hotel & 2 & $4 \%$ \\
Ajudante de Rouparia & 2 & $4 \%$ \\
Atendente de Hotel & 2 & $4 \%$ \\
Auxiliar de Governança & 1 & $2 \%$ \\
Capitão Porteiro & 1 & $2 \%$ \\
Chefe de Segurança & 1 & $2 \%$ \\
Gerente Geral & 1 & $2 \%$ \\
Governanta & 1 & $2 \%$ \\
Coordenador de Reservas & 1 & $2 \%$ \\
Supervisor de Limpeza & 1 & $2 \%$ \\
Vagas administrativas em geral & 1 & \\
\hline & Fonte: Elaborado pelos autores (2016) \\
\hline
\end{tabular}

Fonte: Elaborado pelos autores (2016)

Analisando os dados da tabela 1 e 2 percebe-se que a ocupação de Arrumadeira, por exemplo, é citada tanto como uma vaga com facilidade, mas também com dificuldade de 
contratação. Essa resposta pode estar associada à região onde está sediado o estabelecimento, considerando disponibilidade de pessoas e qualificação disponível na região.

Em relação aos motivos de dificuldade de contratação de pessoal nos meios de hospedagem observou-se na tabela 3 que dois itens se destacam: falta de profissionais qualificados tecnicamente, com $23 \%$, deficiência em relação a competências comportamentais, com $17 \%$. Os dados evidenciam a necessidade de qualificação dos profissionais nos meios de hospedagem não somente em aspectos técnicos, mas na importância de desenvolver também aspectos comportamentais, ou seja, os profissionais precisam investir esforços no autodesenvolvimento.

Tabela 3 - Motivos da dificuldade de contratação de pessoal nos meios de hospedagem

\begin{tabular}{lcc}
\hline \multicolumn{1}{c}{ Motivo } & Quantidade & Porcentagem \\
\hline $\begin{array}{l}\text { Falta de profissionais qualificados tecnicamente } \\
\text { Deficiência em relação a competências comportamentais (ex: }\end{array}$ & 11 & $23 \%$ \\
iniciativa, relacionamento) & 8 & $17 \%$ \\
Falta de conhecimentos em Idiomas & 5 & $10 \%$ \\
Deficiência na formação básica (escolaridade) & 4 & $8 \%$ \\
Trabalhar em horários diferenciados (final de semana, turnos, & & $8 \%$ \\
noite) & 4 & $6 \%$ \\
Falta de interesse dos profissionais em seguir uma carreira no & & $6 \%$ \\
segmento & 3 & $6 \%$ \\
Regras trabalhistas pouco flexíveis para as demandas do segmento & 3 & $4 \%$ \\
Falta de oferta de cursos no segmento na região & 3 & $4 \%$ \\
Escassez de pessoas (baixa oferta de candidatos na região) & 2 & $4 \%$ \\
Falta de experiência para ocupar o cargo & 2 & $2 \%$ \\
Falta de conhecimento em novas tecnologias & 2 & \\
Sazonalidade do segmento (contrata na temporada e depois & & \\
demite) & 1 & \\
\hline
\end{tabular}

Fonte: Elaborado pelos autores (2016)

O planejamento de necessidades de vagas de contratação é fundamental para que uma organização consiga realizar a manutenção dos recursos humanos e garanta os resultados organizacionais. Nos meios de hospedagens (gráfico 1) percebe-se que a maioria dos estabelecimentos, $62,5 \%$, fazem previsão de vagas, sendo que $37,5 \%$ não preveem as vagas que serão necessárias a médio e longo prazo.

Gráfico 1 - Planejamentos de necessidade de vagas nos meios de hospedagem

A empresa realiza planejamento de necessidade de pessoal (previsão de vagas)?

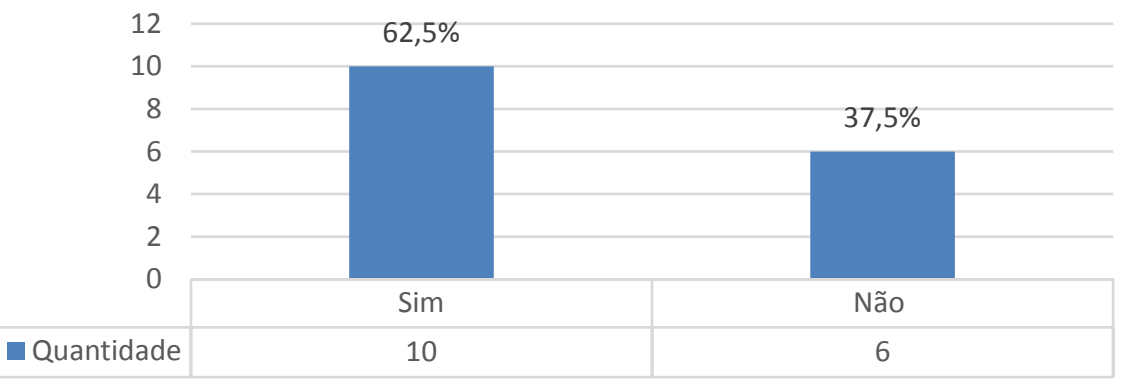

Fonte: Elaborado pelos autores (2016) 
Umas das etapas do processo de atração e seleção de pessoal é a identificação do perfil desejado para a vaga, sendo que o mesmo geralmente está inserido nas descrições de cargos. Observou-se no gráfico 2 que 75\% dos estabelecimentos possuem descrição de cargos com definição do perfil, sendo que somente $25 \%$ não possuem descrição de cargos. Isso evidencia a preocupação do segmento em tentar garantir uma seleção assertiva com mínimo de erros possíveis, pois é através do conhecimento do perfil da vaga que é possível realizar avaliações adequadas.

Gráfico 2 - Meios de hospedagem que possuem descrição de cargos com definição do perfil

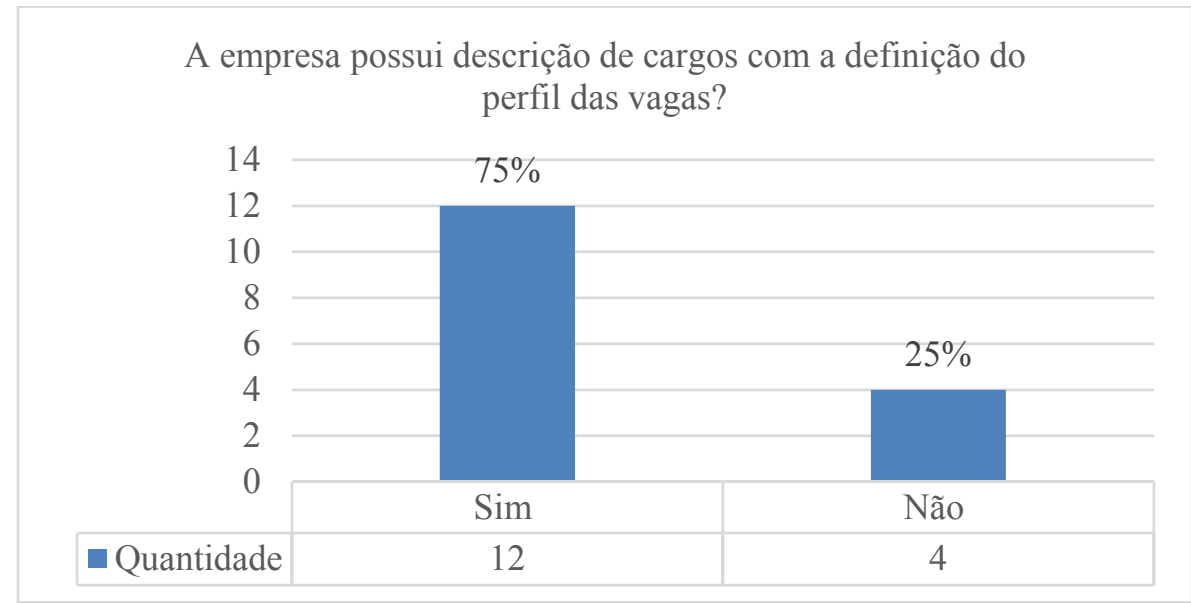

Fonte: Elaborado pelos autores (2016)

Para uma seleção com eficiência é fundamental que se tenha candidatos suficientes para a avaliação. Conseguir candidatos para avaliar é a função do processo de recrutamento, pois quanto maior o número de candidatos, aumentam as possibilidades de selecionar um candidato de acordo com o perfil desejado pela organização. No gráfico 3 é possível verificar que $56 \%$ dos estabelecimentos nos meios de hospedagem utilizam o recrutamento misto, ou seja, oscilam entre o recrutamento interno e externo conforme a necessidade da organização. Uma porcentagem considerável de $31 \%$ utiliza somente o recrutamento interno podendo estar associado a uma estratégia de valorização das pessoas.

Gráfico 3 - Tipos de Recrutamentos utilizados nos meios de hospedagem.

Quais são os tipos de Recrutamento utilizados pela empresa?

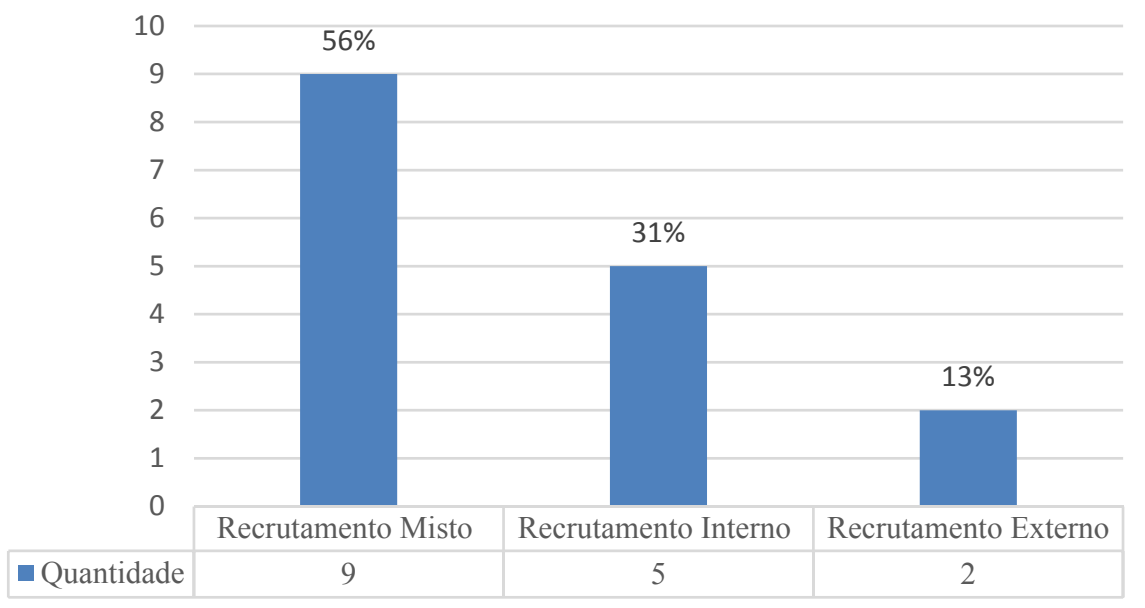

Fonte: Elaborado pelos autores (2016) 
A pesquisa revelou que são utilizadas uma variedade de estratégias para divulgação das vagas, sendo que se destacam anúncios em jornais com $19 \%$ e sites de empregos com $15 \%$. A variedade de estratégias identificada demonstra que o segmento busca alternativas variadas para captação de pessoas.

Tabela 4 - Estratégias de divulgação de vagas nos meios de hospedagem

\begin{tabular}{lrr}
\hline Estratégia & Quantidade & Porcentagem \\
\hline Anúncios em jornais & 9 & $19 \%$ \\
Sites de empregos & 7 & $15 \%$ \\
Anúncios em locais visíveis e de grande circulação & 5 & $10 \%$ \\
Redes sociais e internet & 5 & $10 \%$ \\
Sites corporativos & 5 & $10 \%$ \\
Rádio & 4 & $8 \%$ \\
Bancos de talentos & 3 & $6 \%$ \\
Anúncio em revistas especializadas & 2 & $4 \%$ \\
Divulgação em entidade de classe (sindicatos, associações e & & \\
conselho de classes) & 2 & $4 \%$ \\
Divulgação em escolas, faculdades ou universidades & 2 & $4 \%$ \\
Cadastro de ex-empregados & 1 & $2 \%$ \\
Utilização de agências de emprego & 1 & $2 \%$ \\
Fusões de incorporações & 1 & $2 \%$ \\
Através de currículos & 1 & $2 \%$ \\
\hline
\end{tabular}

Fonte: Elaborado pelos autores (2016)

Os critérios (tabela 5) mais utilizados para seleção de currículos identificados na pesquisa foram: organização do currículo (17\%), tempo de permanência em empregos anteriores (17\%) e descrição das informações claras e organizadas (17\%). Percebe-se que é valorizado a capacidade de o empregado estabelecer vínculo com o empregador, além da capacidade do candidato em confeccionar um currículo bem feito e atrativo.

Tabela 5 - Critérios usados para selecionar currículos.

\begin{tabular}{lcc}
\hline \multicolumn{1}{c}{ Critérios } & Quantidade & Porcentagem \\
\hline Organização do currículo & 8 & $17 \%$ \\
Tempo de permanência em empregos anteriores (estabilidade) & 8 & $17 \%$ \\
Descrição das informações (claras e organizadas) & 8 & $17 \%$ \\
Condução/desenvolvimento da carreira & 6 & $13 \%$ \\
Realizações do candidatos (resultados) & 5 & $11 \%$ \\
Informações em Redes Sociais & 4 & $9 \%$ \\
Lacunas cronológicas & 3 & $6 \%$ \\
Erros gramaticais & 2 & $4 \%$ \\
Fotos inapropriadas & 1 & $2 \%$ \\
Local de residência & 1 & $2 \%$ \\
Falta de informações & 1 & $2 \%$ \\
\hline
\end{tabular}

Fonte: Elaborado pelos autores (2016)

Na tabela 6, é possível identificar que um dos métodos de seleção mais utilizados nos meios de hospedagem é a entrevista. $63 \%$ dos estabelecimentos utilizam mais de um método para selecionar os candidatos tentando garantir uma escolha mais assertiva. No entanto, $37 \%$ dos estabelecimentos utilizam unicamente a entrevista. Segundo Banov (2004, pg. 142) "fazer uso só da entrevista ou de uma única etapa do processo de seleção não garante uma escolha adequada". Nesse sentido, o uso de outros métodos pode auxiliar na identificação e veracidade das informações. 
Tabela 6 - Métodos utilizados no processo de seleção (escolha das pessoas)

\begin{tabular}{lcc}
\hline Métodos & Quantidade & Porcentagem \\
\hline Entrevista & 16 & $47 \%$ \\
Testes de conhecimentos & 8 & $24 \%$ \\
Técnicas de simulação: debates & 2 & $6 \%$ \\
Testes psicológicos & 2 & $6 \%$ \\
Técnicas de simulação: dinâmicas de grupo & 2 & $6 \%$ \\
Técnicas de simulação: role playing (dramatização) & 2 & $6 \%$ \\
Técnicas de simulação: estudos de caso & 1 & $3 \%$ \\
Técnicas de simulação: jogos & 1 & $3 \%$ \\
\hline
\end{tabular}

Fonte: Elaborado pelos autores (2016)

Uma das etapas importantes no processo de seleção é o retorno oferecido para os candidatos no final do processo. Esse retorno deveria ser oferecido considerando que os candidatos têm o direito de conhecer o resultado do processo seletivo.

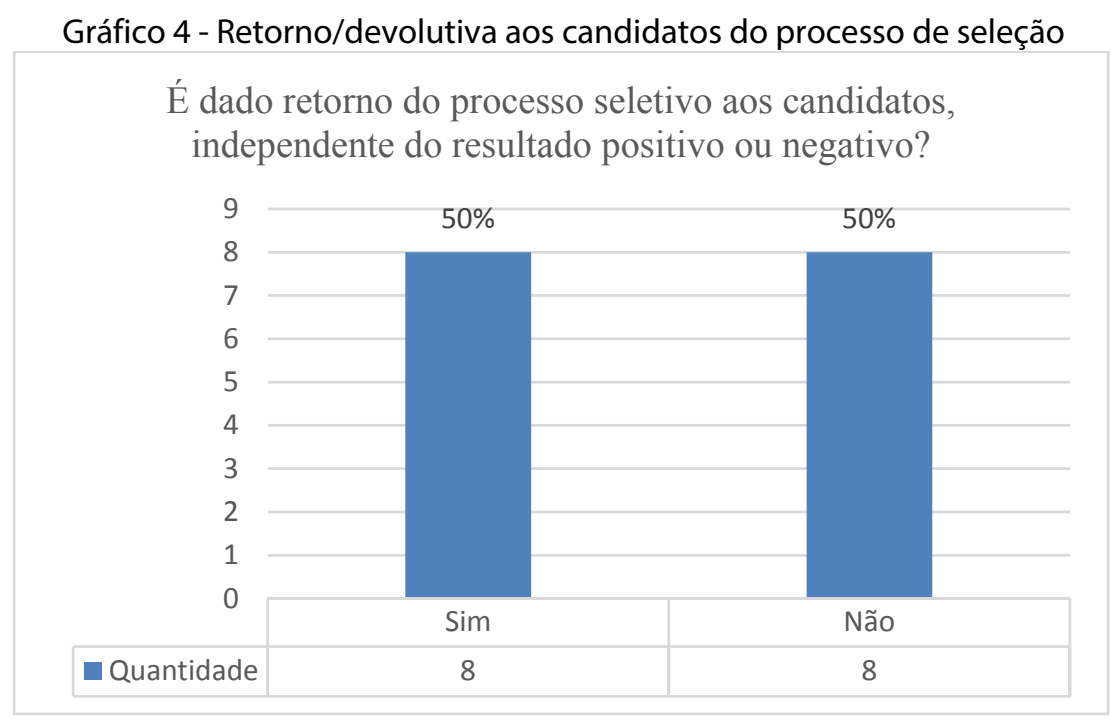

Fonte: Elaborado pelos autores (2016)

Os dados da pesquisa demonstraram que a oferta e demanda de vagas difere de acordo com a localização e características regionais dos meios de hospedagens. Identificou-se que os recursos de atração e seleção podem ser aperfeiçoados favorecendo os resultados das organizações. Além disso, uma das carências dos meios de hospedagem está relacionada à qualificação profissional, ou seja, a necessidade de investir no desenvolvimento de competências técnicas ou comportamentais.

\section{CONCLUSÕES}

O serviço de hospedagem, segundo o IBGE (2012), pertencente a cadeia produtiva da área de turismo, recebe importante destaque pela sua influência, atenção e ação direta ao cliente. As relações estabelecidas entre o cliente ou o turista e os serviços prestados pelos empregados destas organizações têm consequências diretas no nível de satisfação e padrão de qualidade dos envolvidos. Diante disso, a oferta e demanda de pessoas constitui um dos elementos organizacionais que podem garantir de maneira mais efetiva níveis de produtividade adequada e grau de satisfação favoráveis. 


\section{REFERÊNCIAS}

ALBUQUERQUE, Lindolfo Galvão de; LEITE, Nildes Pitombo (Org.). Gestão de Pessoas: perspectivas estratégicas. São Paulo: Atlas, 2009.

BANOV, Maria Regina. Ferramentas da Psicologia Organizacional. 2. ed. São Paulo: CenaUn, 2004.

BRASIL. MINISTÉRIO DO TRABALHO E EMPREGO. Estatísticas básicas de turismo Brasil - ano 2013. Disponível em:

$<$ http://www.dadosefatos.turismo.gov.br/dadosefatos/estatisticas_indicadores/estatisticas_basica s_turismo/>. Acessado em: 11 abr. 2015.

DUTRA, Joel Souza. Gestão de pessoas: modelo, processos, tendências e perspectivas. São Paulo: Atlas, 2002.

FRANÇA, Ana Cristina Limongi. Práticas de Recursos Humanos: conceitos, ferramentas e procedimentos. São Paulo: Atlas, 2010.

GIL, Antonio Carlos. Gestão de Pessoas: enfoque nos papéis profissionais. São Paulo: Atlas, 2010.

SEBRAE. Índice de competitividade do turismo nacional (Recurso eletrônico): destinos indutores do desenvolvimento turístico regional: Relatório Brasil 2014. Brasília, DF: SEBRAE, 2014.

INSTITUTO DE PESQUISA ECONÔMICA APLICADA (IPEA). Perfil da mão de obra no turismo no Brasil nas atividades características do turismo e ocupações. Brasília: Rio de Janeiro: IPEA, 2014.

INSTITUTO DE PESQUISA ECONÔMICA APLICADA (IPEA). Relatório com as estimativas definitivas da ocupação formal e informal em ACTs, para o Brasil e regiões, produzido a partir dos dados da Rais e da Pnad (dados de 2013). Rio de Janeiro: IPEA, 2015.

MELLO, Andreza Sampaio de et al. Práticas de recursos humanos na gestão do setor hoteleiro capixaba. Revista Turismo Visão e Ação, v. 13, n. 3, p. 362-379, set./dez. 2011.

OFFE, C.; HINRICH, K. Economia social do Mercado de trabalho: diferencial primário e secundário de poder. In: OFFE, C. (Org.). Trabalho \& sociedade: problemas estruturais e perspectivas para o futuro da sociedade do trabalho. Rio de Janeiro: Tempo Brasileiro, 1984, p.43-81.

SPECTOR, Paul E. Psicologia nas Organizações. São Paulo: Saraiva, 2004.

VIEIRA, Adriane; PEREIRA, Gilberto Braga; LIMA, Cassia Helena Pereira. Tradição e modernidade nas práticas de recrutamento e seleção e contratação de pessoas em meios de hospedagem. Revista Gestão e Planejamento, Salvador, v. 8, n 2, p. 79-95, jul./dez. 2007.

ZANELLI, José Carlos; BORGES-ANDRADE, Jairo Eduardo; BASTOS, Antonio Virgílio Bittencourt. Psicologia, Organizações e Trabalho no Brasil. Porto Alegre: Artmed, 2004.

PIELLUSCH, Marcos; TASCHNER Gisela Black. Indicadores de RH no setor hoteleiro: um estudo nas maiores redes no Brasil. O \& S, Salvador, v. 16, n. 51, p. 665-686, out./dez. 2009.

GIL, Antonio Carlos. Como elaborar projetos de pesquisa. 4. ed. São Paulo: Atlas, 2002.

LAKATOS, Eva Maria; MARCONI, Marina de Andrade. Fundamentos de metodologia científica. 4. ed. São Paulo: Atlas, 2001. 
SILVA, Edna Lúcia da; MENEZES, Estera Muszkat. Metodologia da pesquisa e elaboração de dissertação. 3. ed. 2001. Disponível em:

$<$ http://cursos.unisanta.br/civil/arquivos/Pesquisa_Cientifica_metodologias.pdf $>$. Acesso em: 10 jul. 2016.

INSTITUTO BRASILEIRO DE GEOGRAFIA E ESTATÍSTICA (IBGE). Pesquisa de serviços de hospedagem 2011: Municípios das capitais, regiões metropolitanas das capitais e regiões integradas de desenvolvimento. Ministério do Turismo. Rio de Janeiro: IBGE, 2012. Disponível em: $<$ http://www.dadosefatos.turismo.gov.br/export/sites/default/dadosefatos/outros_estudos/estudo _ibge_hospedagem/download_ibge_hospedagem/IBGE_-

_Pesquisa_de_Servixos_de_hospedagem_2011_-_Relatxrio_Completo.pdf $>$. Acesso em: 26 out. 2016.

CHIAVENATO, Idalberto. Gestão de Pessoas e o novo papel dos recursos humanos nas organizações. Rio de Janeiro: Elsevier, 2004.

WORLD TRAVEL \& TOURISM COUNCIL (WTTC). Benchmarking Travel \& Tourism Global Summary, Nov. 2013. Disponível em: <http://www.wttc.org/media/files/reports/benchmark\%20reports/2013_global_summary_1.pdf>. Acesso em: 11 abr. 2015.

Nota: Agradecimento ao aluno Marcos Mattos Faculdade Senac Chapecó que participou do planejamento da coleta de dados da pesquisa. 